\title{
Efektivitas Terapi Bermain Fidget Spinner terhadap Nyeri Pasca Operasi Fraktur pada Anak
}

\author{
Abdul Rahman Wange ${ }^{1}$, Andi Arniyanti ${ }^{2}$ \\ ${ }^{1,2}$ Program Studi D-III Keperawatan, Akademi Keperawatan Makassar (YAPMA) \\ Email: abd.wange08@gmail.com
}

Submitted : 12/10/2020

Accepted: 13/11/2020

Published: $06 / 03 / 2021$

\begin{abstract}
Fracture is one of the most vulnerable injuries in children. Fracture is a disconnectionin bone continuity caused by trauma or physical exertion, the management of the fracture can be done with orthopedic surgery, namely by open reduction using internal fixation. Pain is a major problem in post operative fracture care Non pharmacological techniques that can be done to ward off postoperative pain in children are by doing play therapy, one of which is by using fidget spinner therapy. This literature review aims to analyze the effect of fidget spinner therapy on postoperative fracture pain.this game can distract children and give them something soothing to release pent up energy. Methods: This research explores quantitative evidence published in electronic databases such as pubmed, garuda, and google schoolar. Using a journal search strategy, I only came up with the results of one recent and relevant journal for inclusion in the final analysis. Results: I can see a significant effect in postoperative fracture pain intensity in the child after the patient was given fidget spinner therapy. Conclusion: From the results, it can be concluded that fidget spinner therapy is a non-pharmacological therapy that can reduce the pain scale in post operative fracture patients. It is hoped that parents will use this game in the handling of fracture pain in their children.
\end{abstract}

Keyword: fracture, fidget spinner, pain

\begin{abstract}
Abstrak
Kasus fraktur termasuk salah satu cedera yang sangat rentan terhadap anak-anak. Fraktur atau patah tulang merupakan terputusnya rusaknya tulang yang diakibatkan oleh adanya trauma atau tenaga fisik, penatalaksanaan pada fraktur dapat dilakukan dengan pembedahan orthopedi yaitu dengan reduksi terbuka menggunakan fiksasi secara interna. Nyeri merupakan masalah utama dalam perawatan paska pembedahan fraktur, teknik non farmakologi yang dapat dilakukan untuk menangkal nyeri paska operasi pada anak yaitu dengan melakukan terapi bermain salah satunya dengan menggunakan terapi fidget spinner. Tinjauan pustaka ini bertujuan menganalisis efek terapi fidget spinner terhadap nyeri paska operasi fraktur. Permainan ini dapat mengalihkan perhatian anak-anak dan dapat memberikan mereka ketenangan untuk melepaskan energi yang mereka pendam. Metode: Penelitian ini mengeksplorasi bukti kuantitatif yang diterbitkan dalam database elektronik seperti pubmed, garuda, dan google schoolar. Dengan menggunakan strategi pencarian jurnal, saya hanya mendapatkan hasil satu jurnal yang berpotensi dan relevan untuk dimasukkan dalam analisis terakhir. Hasil: Saya dapat melihat efek yang signifikan dalam intensitas nyeri paska operasi fraktur pada anak setelah pasien diberikan terapi fidget spinner. Kesimpulan: dilihat dari hasil dapat disimpulkan bahwa terapi fidget spinner adalah terapi non farmakologi yang dapat menurunkan skala nyeri pada pasien post operasi fraktur. Diharapkan kepada orang tua agar menggunakan permainan ini dalam penanganan nyeri fraktur pada anaknya.
\end{abstract}

Kata kunci: fraktur, fidget spinner, nyeri 


\section{PENDAHULUAN}

Setiap manusia mempunyai pertahanan tubuh yang berbeda-beda. Bahkan, bahan yang digunakan untuk mendirikan tubuh kita pula berbeda, Jika terjadi benturan-benturan kecil sekalipun, akan menyebabkan fraktur (Julaeha, 2019). Fraktur atau patah tulang adalah rusaknya kontinuitas tulang yang diakibatkan oleh trauma atau tenaga fisik, fraktur terjadi jika tulang terkena stress yang lebih besar dari yang dapat diabsorbsinya, yang diakibatkan oleh pukulan langsung, gaya meremuk, gerakan secara tiba-tiba dan kontak siototekstern(Hastriati, 2019). Kerusakan tulang atau fraktur terjadi pada masyarakat umum karena adanya dampak mekanis atau kelainan pada tulang (Nugraha \& Hidayat, 2019). Kasus patah tulang juga termasuk salah satu cedera yang sangat rentan terhadap anak-anak, Sebuah sensus pemerintah menyatakan bahwa kontribusi tertinggi kasus patah tulang di Indonesia adalah anak yang berumur 17 tahun kebawah (Sya'ban et al., 2017).

Menurut data angka kejadian fraktur di dunia masih cukup tinggi, World Health Organization (WHO) mencatat di tahun 2010 kasus fraktur menjadi 21 juta orang (Puspita, 2018), pada tahun 2011 tercatat lebih dari 5,6 juta orang meninggal dunia disebabkan oleh kecelakaan dan sekitar 1,3 juta orang menderita cacat fisik. Insiden fraktur ekstremitas bawah memiliki prevalensi yang tinggi pada kecelakaan yaitu sekitar 40\% (Susanti et al., 2019). Fraktur berada di urutan ketiga setelah penyakit jantung kotoner dan tuberculosis yang menjadi penyebab kematian terbanyak di Indonesia (Wulandini et al., 2018). Berdasarkan survey dari Lembaga Kesehatan RI tahun 2013 ditemukan sekitar delapan juta orang mengalami fraktur berdasarkan jenis dan penyebab yang berbeda-beda, dimana sebanyak $10 \%$ mengalami kesembuhan dengan baik, $15 \%$ mengalami stress psikologis, $45 \%$ menderita cacat fisik, dan sebanyak $25 \%$ orang kehilangan nyawa (Risnah et al., 2019).

Di Sulawesi Selatan berdasarkan profil Dinas Kesehatan 2014, diperoleh dari 44 Rumah Sakit kabupaten/kota yang berada di Sulawesi Selatan (Pemerintah dan Swasta) melaporkan kasus Penyakit Tidak Menular tahun 2013 ditemukan bahwa kecelakaan lalu lintas merupakan kasus fraktur terbanyak dimana kasus rawat jalan sebanyak 9.354 dan kasus rawat inap sekitar $3.842 \quad$ (Kombong, 2018). Pembedahan merupakan salah satu tindakan yang dilakukan untuk mengembalikan struktur dan fungsi tulang menjadi normal kembali (Setiani, 2017). Pembedahan pada fraktur dilakukan dengan cara reduksi terbuka menggunakan fiksasi secara interna (O.R.I.F.), tujuannya untuk mempertahankan bagian tulang tetap pada posisinya sampai tulang dalam keadaan membaik (Nopianti et al., 2019).

Keluhan utama yang dirasakan oleh pasien dalam perawatan paska operasi fraktur adalah nyeri, hal ini disebabkan oleh adanya kerusakan jaringan sehingga individu akan bereaksi dengan cara memindahkan stimulus nyeri (Utami, 2016).Anak usia sekolah cenderung lebih sensitif, aktif dan sangat agresif pada saat mengalami nyeri yang sering kali sulit untuk diketahui oleh orang tua dan petugas (Azari et al., 2016). Manajemen nyeri dapat dilakukan melalui manajemen farmakologi dan manajemen non farmakologi (Sarim \& Suryono, 2019). Salah satu tindakan farmakologi yang dapat dilakukan adalah dengan cara pemberian analgetik berupa ketorolak injeksi (Nurani \& Yanti, 2020). Obat ini diberikan pada anak dengan dosis $1 \mathrm{mg} / \mathrm{kg}$ sebagai single dose(Ramadhani et al., 2019). Namun, penggunaan obat ketorolak memiliki efek samping seperti mual dan muntah, terutama jika penggunaannya tidak tepat (Handayani et al., 2019). Untuk meminimalisasi efek samping dari terapi 
farmakologi tersebut dikembangkan terapi non farmakologi dengan melakukan terapi bermain pada anak-anak, Salah satu terapi yang cocok adalah terapi bermain fidget spinner (Yudhaningtyas \& Hartini, 2019).

Fidget Spinner (FS) adalah terapi bermain yang terbuat dari logam atau plastik dan terdiri dari bantalan tengah yang dikelilingi oleh tiga bantalan lengan, yang berputar mengelilingi bagian tengah (Tipnis \& Ciecierega, 2018). Fidget Spinner berputar pada sumbu pusat, yang dihasilkan oleh dua cincin. Dengan menggunakan mekanisme bantalan bola alih-alih hanya menggeser antar cincin, gesekannya dapat berkurang secara signifikan selama berputar. Untuk lebih meningkatkan lamanya putaran, fidget spinner dilengkapi dengan tiga sayap berlubang yang membawa beban yang didistribusikan secara merata dari tengah(Cohen et al., 2018). Mainan ini dapat menghasilkan pola memutar yang menarik, semakin unik desain dari permainannya maka pola yang dihasilkan akan lebih menarik. selain itu, permainan ini juga dapat mengalihkan perhatian anakanak dan memberi mereka sesuatu yang menenangkan untuk melepaskan energi yang terpendam (Alfirahmi \& A.R., 2018). Permainan ini dapat menstimulasi peningkatan hormon endorfin yang merupakan unsur sejenis morfin yang dikeluarkan oleh tubuh untuk mengurangi nyeri (Mayenti \& Sari, 2020).

Berdasarkan uraian diatas penelitian ini bertujuan untuk menganalisis efek terapi fidget spinner terhadap nyeri paska operasi fraktur pada pasien anak.

\section{METODE PENELITIAN}

Pencarian literatur ditemukan berdasarkan pencarian hasil-hasil publikasi ilmiah pada rentan tahun 2015-2020 dengan mengambil artikel melalui database pubmed, garuda, dan google scholar. Pada database pubmed dimasukkan Keyword 1 "fracture"ditemukan hasil 107.406 artikel, keyword 2 "pain" didapatkan hasil 394.054 artikel, keyword 3 "fidget spinner" ditemukan hasil 12 artikel. Kemudian penulis menggabungkan keyword 1, 2 dan 3 "Frakture AND pain AND fidget spinner" didapatkan hasil 0 jurnal. Pada pencarian data base melalui garuda dimasukkan keyword 1 "fraktur" ditemukan hasil 169 artikel, Keyword 2 "nyeri" ditemukan hasil 1.700 artikel, keyword 3 "fidget spinner" ditemukan hasil 1 artikel. Kemudian dilakukan penggabungan keyword 1,2 dan 3 "Fraktur, nyeri dan fidget spinner" didapatkan hasil 0 jurnal.

Sedangkan pada pencarian melalui database google scholar dimasukkan kata kunci 1 "fraktur" ditemukan hasil 15.700 artikel, kata kunci 2 "nyeri" ditemukan hasil 17.900 artikel, kata kunci 3 "fidget spinner" ditemukan hasil 1.030 artikel. Kemudian menggabungkan kata kunci 1,2 dan 3 ditemukan hasil 1 artikel. Dari hasil pencarian ditemukan hanya satu artikel yang relevan dengan pertanyaan peneliti.

\section{HASIL DAN PEMBAHASAN}

Berdasarkan hasil penelitian yang dilakukan oleh Nazla, (2018) yang berjudul "Pengaruh Terapi Bermain Fidget Spinner Terhadap Nyeri Anak yang Mengalami Pasca Operasi Fraktur" yang bertujuan untuk mengetahui pengaruh pemberian terapi bermain Fidget spinner terhadap intensitas nyeri pada pasien post operasi fraktur yang dilakukan di RS. Putri Hijau Medan pada tahun 2018. Dengan menggunakan Jenis penelitian Quasi eksperimen pre-test dan post-test design. Jumlah sampel 49 responden diambil dengan menggunakan teknik accidental sampling. Pada hasil analisis dapat diketahui bahwa antara variabel skala nyeri sebelum diberikan terapi bermain dengan anak yang telah diberikan terapi bermain didapatkan nilai t-hitung sebesar 13,416 dengan $\mathrm{p}$ value sebesar $0,001(\mathrm{p}<\alpha)$, dan 
dengan nilai interval kepercayaan (2,0312,622) yang berarti bahwa ada pengaruh secara signifikan antara terapi bermain terhadap tingkat nyeri pada klien pasca pembedahan patah tulang sebelum dan setelah dilakukan terapi bermain.

\section{Pembahasan \\ Fraktur}

Fraktur dapat dikatakan suatu ancaman potensial maupun aktual terhadap inegritas seseorang (Mandagi et al., 2017). Menurut ilmu kedokteran fraktur merupakan suatu retakan atau lebih, yang biasanya retakan itu lengkap atau fragmennya hanya bergeser dari posisinya (Sudayasa et al., 2018).Penyebab fraktur secara umum dapat disebabkan oleh penyebab ekstrinsik antara lain trauma langsung, trauma tidak langsung, bending, torsional, dan kompresi. penyebab intrinsik antara lain akibat kontraksi otot dan kondisi patologis (Prasetyo \& Pratiwi, 2019).

Menurut Andri et al., (2020) klasifikasi fraktur berdasarkan kontak dengan dunia terbagi menjadi fraktur terbuka (fraktur yang merusak jaringan kulit) dan fraktur tertutup (fraktur yang tidak keluar melalui kulit). Prinsip dasar penanganan fraktur dilakukan dengan konsep 4R, yaitu rekognisi (mengenali fraktur yang terjadi), reduksi (menempatkan kembali pada posisinya), retensi (mempertahankan posisi), dan merehabilitasi (Erwin et al., 2019). Dalam sebuah artikel penelitian yang dilakukan oleh (Lestari, 2017) pada bulan Juli 2011 hingga bulan September 2011 sebanyak 36 pasien penderita fraktur menjalani pembedahan $O R I F$, ditemukan sebagian besar dari mereka mengalami komplikasi post operasi seperti nyeri, kesemutan, bengkak atau edema, dan pucat pada daerah yang di operasi.

\section{Nyeri}

Nyeri pasca pembedahan fraktur akan dilanjutkan dengan perawatan pemberian terapi obat analgesik (Firdaus, 2020). Luka setelah operasi yang tidak diberikan perawatan secara maksimal dapat memperlambat penyembuhan dan menimbulkan komplikasi berupa adanya proses inflamasi akut yang menyebabkan keterbatasan gerak (Permana et al., 2016). Nyeri merupakan reaksi pertama dirasakan oleh seseorang pada saat mengalami cidera. Nyeri dapat diklasifikasikan menjadi nyeri akut dan nyeri kronik (Martini et al., 2018). Nyeri akut merupakan nyeri yang muncul secara mendadak dan dirasakan kurang dari 6 bulan. Sementara nyeri kronis adalah nyeri yang terus-menerus berlangsung selama lebih dari enam bulan dan timbul secara perlahan-lahan (Pujianto \& Zainuddin, 2019).

Nyeri dapat dirasakan karena adanya stimulus yang diterima oleh nociceptors pada kulit. ketika terjadi cedera, lesi akan mengaktifkan faktor pembeku darah sehingga bradikinin dan serotonin akan terstimulasi dan menstimulasi nociceptor (Bahrudin, 2018). Respon nyeri pada anak sangat bervariasi karena dipengaruhi berbagai faktor diantaranya adalah faktor usia anak, jenis kelamin, pengalaman nyeri sebelumnya, dan dukungan dari keluarga dengan memberikan pendampingan pada anak. Meski masih diragukan juga bahwa faktor jenis kelamin dapat mempengaruhi rasa nyeri pada anak (Padhila \& Jusmani, 2019). Dalam pengukuran tingkat nyeri sangat subjektif dan bersifat perseorangan, sehingga dua orang yang berbeda dapat mengekspresikan intensitas nyeri yang sama dengan cara yang berbeda (Astutik \& Kurlinawati, 2017).

Menurut Asriani et al., (2017), Nyeri apabila tidak ditangani akan memberikan berdampak besar bagi kehidupan anak seperti, mengganggu aktivitas anak dan mereka akan mengalami kesulitan dalam berinteraksi dengan orang lain sebab anak hanya fokus pada rasa sakit yang mereka rasakan. Manajemen nyeri dapat dibedakan menjadi teknik farmakologi dan non 
farmakologi, teknik farmakologi merupakan metode yang dilakukan untuk mengurangi nyeri dengan menggunakan terapi obat-obatan (Hastomo \& Suryadi, 2019). Sementara penanganan nyeri secara non farmakologi dapat dilakukan dengan berbagai macam jenis distraksi sperti distraksi penglihatan, perabaan/sentuhan, teknik napas dalam, imajinasi terbimbing dan distraksi intelektual (Wardah et al., 2019). Penggunaan teknik non farmakologi memberikan efek yang cukup baik dalam penanganan nyeri pada anak, salah satunya dengan menggunakan terapi bermain (Novitasari et al., 2019).

\section{Terapi Bermain Fidget Spinner}

Pada saat anak dirawat di ruang perawatan, anak akan merasakan stress dan juga nyeri (Saputro \& Fazrin, 2017). Terapi bermain merupakan salah satu kegiatan yang bertujuan untuk membantu proses penyembuhan anak dan sebagai sarana dalam mengoptimalkan pertumbuhan serta perkembangan anak (Ihsan et al., 2018).

Di eramilenial ini, kegiatan bermain dengan media permainan modern seperti Uno Stacko Tower, Gedget, dan Game Online, fidget Spinner banyak digunakan oleh anak-anak (Yudhaningtyas \& Hartini, 2019). Fidget Spinner muncul di pasaran pada awal 2017 dan menjadi populer dengan cepat,pemasaran awal menargetkan anak-anak dengan gangguan hiperaktif defisit perhatian; Namun, gadget ini telah menarik minat anak-anak dari berbagai rentang usia(Khalaf et al., 2018). Fidget spinner dapat memfasilitasi interaksi sosial dan percakapan di antara anak-anak yang berpikiran sama dan dapat digunakan untuk mengurangi stres selama prosedur (Schecter et al., 2017).

Fidget spinner merupakan mainan yang memiliki bantalan bola di tengah struktur datar multi-lobed dibuat dari logam maupun plastik, disusun untuk berputar di sepanjang porosnya (Liu et al., 2019). Bantalan pusat dipegang di antara 2 jari saat pod berputar, Mereka biasanya mengukur diameter beberapa sentimeter (Koo \& Tamura, 2018). Teknik bermain fidget spinner dilakukan dengan cara memegang bantalan yang berada di bagian tengah dari spinner dan memutar spinner dengan cara memutar polong dengan jentikan jari. Putaran spinner tergantung pada kualitas bantalan spinner dan gaya awal memutar. Semakin kecil gesekan dari bantalan maka akan semakin lama spinner berputar (Suwarno, 2018). Penggunaan terapi bermain fidget spinner dapat merangsang seseorang untuk memandang satu titik secara terus-menerus sehingga menyebabkan seseorang dapat terfokus pada situasi tersebut, hal ini mengurangi stress (Budiyanta et al., 2019).

\section{SIMPULAN}

Berdasarkan hasil penelitian dari literature review ini terlihat bahwa terapi bermain fidget spinner efektif dalam penanganan nyeri fraktur femur pada anak. Hal ini dapat dilihat dari perbandingan antara variabel skala nyeri sebelum dan setelah mendapatkan terapi fidget spinner. Selain itu, permainan ini juga mudah untuk dimainkan dan tidak menggunakan biaya yang banyak.

\section{SARAN}

Diharapkan kepada para orang tua agar menggunakan permainan ini dalam penanganan nyeri fraktur pada anaknya. Literatur Review ini membutuhkan penelitian lebih banyak lagi untuk memperoleh hasil yang memuaskan. Fidget Spinner sangat direkomendasikan untuk penelitian studi kasus atau kuantitatif di kota Makassar karena sebelumnya penelitian ini belum pernah dilakukan di kota Makassar.

\section{DAFTAR PUSTAKA}

Alfirahmi, \& A.R., H. F. (2018). Fenomena Fidget Spinner Ditinjau Dari Sudut Pandang Konsumerisme dan Kultivasi. Jurnal Lugas, 2(1), 33-41. 
https://doi.org/ISSN: 2580-8338

Andri, J., Febriawati, H., Padila, Harsismanto, \& Susmita, R. (2020). Nyeri Pada Pasien Post Operasi Fraktur Ekstremitas Bawah Dengan Pelaksanaan Mobilisasi Dan Ambulasi Dini. Journal of Telenursing, 2(1), 61-70. https://doi.org/10.1017

Bahrudin, M. (2018). Patofisiologi Nyeri (Pain). Saintika Medika, 13(1), 7-13. https://doi.org/10.22219

Cohen, E. J., Bravi, R., \& Minciacchi, D. (2018). The effect of fidget spinners on fine motor control. Scientific Reports, $\quad 8(1), \quad 1-9$. https://doi.org/10.1038

Firdaus, M. (2020). Efektivitas Teknik Distraksi Musik Klasik Mozart Untuk Mengurangi Nyeri Pada Pasien Post Operasi Fraktur. Journal of STIKes Awal Bros Pekanbaru, 1(1), 41-47. https://doi.org/ISSN: 2721-5172

Handayani, S., Arifin, H., \& Manjas, M. (2019). Kajian penggunaan analgetik Pada Pasien Pasca Bedah Fraktur. JSFK (Jurnal Sains Farmasi \& Klinis), 6(2), 113-120. https://doi.org/10.25077

Khalaf, R. T., Gurevich, Y., Marwan, A. I., Miller, A. L., Kramer, R. E., \& Sahn, B. (2018). Button Battery Powered Fidget Spinners: A Potentially Deadly New Ingestion Hazard for Children. Journal of Pediatric Gastroenterology and Nutrition, 66(4), 595-597.

Koo, J., \& Tamura, D. Y. (2018). Fidget Spinner Battery-LED Unit Ingestion in a 13-Month-Old Boy. Clinical Pediatrics (Phila), 57(7), 1-4. https://doi.org/10.1177/000992281773 3302

Mandagi, C. A. F., Bidjuni, H., \& Hamel, R. S. (2017). Karakteristik Yang Berhubungan Dengan Tingkat Nyeri Pada Pasien Fraktur Di Ruang Bedah Rumah Sakit Umum Gmim Bethesda Tomohon. E-Journal Keperawatan (eKp), 5(1). https://doi.org/ISSN: 2302-
1152

Martini, M., Watiningsih, Pertama, A., \& Lisnayani, K. (2018). Terapi distrkasi terhadap penurunan nyeri. Jurnal Kesehatan, 7 no 2 (september), 353360.

https://doi.org/10.24252/kesehatan.v7i 2.54

Mayenti, F., \& Sari, Y. (2020). Efektifitas Teknik Distraksi Musik Klasik Mozart Untuk Mengurangi Nyeri Pada Pasien Post Operasi Fraktur. Jurnal Akademika Baiturrahim Jambi, 9(1), 98.

https://doi.org/10.36565/jab.v9i1.193

Nazla, N. (2018). Pengaruh Terapi Bermain Fidget Spinner Terhadap Nyeri Anak yang Mengalami Pasca Operasi Frakturi [Universitas Sumatra Utara]. In Repositori Institut USU. http://repositori.usu.ac.id/handle/1234 56789/8164

Nopianti, W., Setyorini, D., \& Pebrianti, S. (2019). Gambaran Implementasi Perawat dalam Melakukan Mobilisisasi Dini pada Pasien Post Operasi ORIF Fraktur Ekstremitas Bawah di Ruang Orthopedi RSUD dr. Slamet Garut. Manuju: Malahayati Nursing Journal, 1(2), 196-204. https://doi.org/ISSN: 2655-2728

Padhila, N. I., \& Jusmani, A. (2019). Faktor Yang Mempengaruhi Tingkat Nyeri Anak Usia 7-13 Tahun Saat Dilakukan Pemansangan Infus. Bina Generasi: Jurnal Kesehatan, 11(1), 40-45. https://doi.org/10.35907

Permana, O., Nurchayati, S., \& Herlina. (2016). Pengaruh Range Of Of Motion (ROM) Terhadap Intensitas Nyeri Pada Pasien Post Operasi Fraktur Ekstremitas Bawah. Jurnal Online Mahasiswa Program Studi Ilmu Keperawatan Universitas Riau, 2(2), 1327-1334. https://doi.org/ISSN: $1327-1334$

Pujianto, R. A., \& Zainuddin, R. (2019). Penerapan Terapi Musik Klasik Dalam 
Menurunkan Nyeri Pada Pasien $\mathrm{Ca}$ Mammae Literaure Review. ( $\mathrm{Jkg}$ ) Jurnal Keperawatan Global, 4(2), $115-120$.

https://doi.org/10.37341/jkg.v4i2.68

Puspita, N. A. Y. U. (2018). Pengaruh Aromaterapi Lavender dan Genggam Jari Terhadap Intensitas Nyeri Post Operasi Fraktur. Universitas Muhammadiyah Surakarta.

Ramadhani, A. N., Istikarini, I. F., \& Irwan, M. (2019). Terapi Non Farmakologi dalam Penanganan Diagnosis Nyeri Akut pada Fraktur: Systematic Review. Journal Of Islamic Nursing, 4(2), 77-87. https://doi.org/ISSN: 2549-5127

Saputro, H., \& Fazrin, I. (2017). Anak Sakit Wajib Bermain Di Rumah Sakit: Penerapan Terapi Bermain Anak Sakit; Proses, Manfaat dan Pelaksanaannya (E. A. Yalestyarini (ed.); 1st ed.). Forum Ilmiah Kesehatan. https://doi.org/10.20527

Schecter, R. A., Shah, J., Fruitman, K., \& Milanaik, R. L. (2017). Fidget spinners: Purported benefits, adverse effects and accepted alternatives. Current Opinion in Pediatrics, 29(5), 616-618. https://doi.org/10.1097

Susanti, S., Widyastuti, Y., \& Sarifah, S. (2019). Pengaruh Terapi Murottal AlQur 'an Untuk Menurunkan Nyeri Post Operasi Fraktur Ekstremitas Bawah Hari Ke 1 The Effect Of " Murottal Al- Qur' an " Therapy To Decrease Pain Of Lower Extremity Fracture Post Operation Day 1. Indonesian Journal On Medical Science, 6(2), 57-62. https://doi.org/ISSN: 2355-1313

Tipnis, N. A., \& Ciecierega, T. (2018). Fidget Spinner Ingestion. Journal of Pediatric Gastroenterology and Nutrition, 66(4), 111-112. https://doi.org/10.1097

Wulandini, P., Roza, A., \& Safitri, S. R. (2018). Efektifitas Terapi Asmaul Husna Terhadap Penurunan Skala Nyeri Pada Pasien Fraktur Di Rsud Provinsi Riau. Jurnal Endurance, 3(2), 375-382. https://doi.org/10.22216 